\title{
MICHEL FOUCAULT Y EL SABER PODER
}

Edgard Palazio Galo

\section{Resumen}

El constructo analítico de Foucault permitió descubrir la profunda relación existente entre el poder y el saber, sustrayendo del saber su presupuesto de neutralidad. El saber requiere un entramado de poder para su concreción y a la inversa, siendo a su vez el saber un producto del poder.

La propuesta de Foucault nos da visos de acción y análisis de vigencia singular, validos hoy día como en el futuro, sobre todo en los marcos de condicionalidad politicas aparentemente normativas del sistema capitalista y su posicionamiento teórico neoliberal que han dejado, supuestamente, sin base a gran parte de las propuestas teóricas alternativas.

Si bien la relación de poder-saber se deja ver objetivada en el sujeto, es indudable también, la gran carga que lleva sobre si la institución del Estado como matriz de un modelo normativo que también individualiza. Esto hace que la propuesta deba ser la consecución de la libertad tanto del modelo de Estado como de la forma individualizante que dimana de este, en un horizonte posible dando lugar a otra subjetividad.

El pensamiento de Foucault adquiere en nuestro tiempo mayor interés y utilidad, en especial su forma de analizar las relaciones de poder brindan un marco teórico que da pista para la realización de estudios más integrales que tomen como referentes los diversos tejidos culturales o sociales que marcan los mecanismos de control, ocultos tras la modernidad tecnológica de nuestras sociedades.

Palabras claves: saber, poder, sistema capitalista, sujeto.

\begin{abstract}
Foucault's analytical basis allowed discovered the deep relationship between power and knowledge, subtracting knowledge 'neutrality. Requires knowledge a power 's framework for concetions and inversely, being in turn knowledge a product of power.

Foucault proposal gives overtones of actions and analysis of singular validity, valid today and future, especially in in the context of politic conditionality, capitalist regulations and its neoliberal positioning which have left, without basis the theoretical alternatives proposal.

The ratio power - knowledge materialized in the subject, it is clear the weight in the Estate institution, as matrix of a formative model that also individualized. This does the proposal should be achieving freedom of the Estate model as the individualizing emanating from this, proposing a possible horizon to give another subjectivity.

Foucault thought becomes more interesting and useful especially its way of analysing power relations. Provides a theoretical framework-giving track for more comprehensive studies, providing a reference to the various social network that guide hidden control mechanisms after technological modernity of our societies.
\end{abstract}

Keyword: knowledge, power, capitalist system, subject. 
"Quizás haya que renunciar (...) a toda una tradición que deja imaginar que no puede existir un saber sino alli donde se hallan suspendidas las relaciones de poder (...) Hay que admitir (...) que el poder produce saber (...) que poder y saber se implican directamente el uno al otro (...)". (Foucault, Michel, 2000)

"estamos (...) en la máquina panóptica, dominados por sus efectos de poder que prolongamos nosotros mismos, ya que somos uno de sus engranajes." (Foucault, Michel, 2000)

\section{Introducción}

$\mathrm{M}$ ichel Foucault nos permitió con su "mirada", ver mas allá de los supuestos sostenidos en las ciencias sociales que admitían la existencia de una forma de poder único del cual eran depositarios esenciales, el Estado o las élites dirigentes. Con este intelectual francés se iluminó el escenario social y descubrió tras bambalina los hilos que permiten interpretar como la sociedad establece mecanismos disciplinarios de control y el ejercicio del poder no está únicamente centralizado en el Estado, sino que se experimenta en todas partes del entramado social.

Constituye una perspectiva epistémica de gran magnitud, el aproximarse desde el otro lado del espejo, al tema de las relaciones de poder, en oposición a la tradición histórica del modelo explicativo de poder central.

El contructo analítico de Foucault permitió descubrir la profunda relación existente entre el poder y el saber, sustrayendo del saber su presupuesto de neutralidad y exponerlo como construcción activa portadora de condicionalidades e intereses. El saber requiere un entramado de poder para su concreción y a la inversa, siendo a su vez el saber un producto del poder.

Esta aquiescencia del saber-poder se establece como estrategia discursiva, el poder tiene la potesta de articular y legitimar discursosquea su vezseconcretan en saberes. Son prácticas sociales en tanto acciones intersubjetivas que controlan, ya transformando o conservando, el tipo de poder generado a partir de discursos objetivados en saberes. Su finalidad se manifiesta en el sujeto en tanto ser social inserto dentro de un esquema mas amplio del proceso formativo-correctivo de disciplinamiento de la sociedad moderna.

Desde la perspectiva foucoltiana, la realidad se construye por el saber en tanto construcción social legitimada por el poder, siendo el saber un instrumento determinado por la voluntad de dominio que produce una acción disciplinaria. De esta manera el poder se materializa a través de diversas representaciones de disciplinamiento, diversas formas de vigilancia y control.

Un acto de violencia normativa tiene lugar, sobre los sujetos que introyectan, aun sin saberlo, la subjetividad impuesta por las estructuras de poder, asimilando y reproduciendo la situación de dominación como algo natural.

Se puede resumir que la "disciplina fabrica individuos; siendo la técnica especifica de un poder que se da en los individuos a la vez como objetos y como instrumentos de su ejercicio," (Foucault, Michel, 2000). Esta función es facilitada por prácticas discursivas dominantes a través de 
las cuales el saber genera un resultado objetivante. Se estructuran en lo sucesivo dispositivos coercitivos no visibles sobre los cuales mantiene permanencia activa el poder. Podríamos decir que esta relación logra establecer una funcionalidad dialéctica: saber-poder/poder-saber.

El conjunto de las prácticas discursivas y el acto de conocer dejan ver sustantivamente una acción sobre los sujetos. No es un flujo neutro, encierra horizontes bien claros de reproducción de mecanismos de reforzamiento del dominio disciplinario sobre los cuerpos, con la habilidad de mantenerse "ni demasiado concentrado en algunos puntos privilegiados, ni demasiado dividido entre unas instancias que se oponen: que esté repartido en circuitos homogéneos susceptibles de ejercerse en todas partes, de manera continua, y hasta el grano más fino del cuerpo social". (Foucault, Michel, 2000).

\section{Foucault y el saber poder}

Es claro que el poder se construye y manifiesta en los discursos producidos dentro del circuito entretejido por la relación sujeto y grupos, ejerciendo dominio sobre sus acciones. Su resultado reproduce-modifica el comportamiento disciplinario deseado por el saber poder que el sujeto auto percibe como natural en su acción cotidiana. Cotidianidad que imperceptiblemente ha dejado de ser propia, cotidianidad vigilada a profundidad por el saber-poder cuya finalidad reside en lograr la formación requerida del sujeto como fuerza útil de "acuerdo con toda una táctica de las fuerzas y de los cuerpos." (Foucault, Michel, 2000).

Es un poder que a la vez de subyugar constituye al sujeto subsumiéndolo a comportamiento y prácticas disciplinadas. Es la inmanencia del panóptico que se encarga de ajustar la modelación que precisa-requiere la relación del poder con la vida cotidiana. Cotidianidad constituida en correspondencia con la función articuladora que ejerce la formación discursiva que da legitimidad a la práctica diaria de acciones disciplinarias.

De manera que el origen o monopolio del poder no se encuentra de forma exclusiva en el Estado como entidad supra estructural. Reducir el poder a algo que se puede tener, una especie de externalidad del sujeto, es discutible y no sería tan atinado desde esta perspectiva. El poder no se localiza en un sitio determinado, lo es en virtud de su relación funcional consustancial al individuo $y$ sus manifestaciones conductuales.

Con este enfoque Foucault propone un horizonte de análisis que nos sitúa más allá de la interpretación lineal argumentada desde posiciones teóricas basadas en determinismos históricos. Muchas de ellas adolecían de perspectiva y alcance suficiente para ver la naturaleza del tipo de poder introyectado en los sujetos, y la funcionalidad de esta forma de poder totalizante a la vez que individualizante. Sin estas herramientas teóricas los enfoques alternativos de izquierda, terminaban reproduciendo o refuncionalizando los rituales y prácticas de poder contra las cuales, precisamente fundamentaban gran parte de su lucha.

En Foucault el poder en tanto conjunto de relación, existe cuando es puesto en acción. Su función se define por su no operación directa e inmediatamente, sino por su carácter relacional. Sus dispositivos están presentes en todos los niveles de la sociedad. Es imposible escaparse, está introyectado y actúa en cada poro social, en cada espacio privado o cotidiano, incluyendo el cuerpo mismo. El poder 
en este sentido, es carcelario y nuestros contructos subjetivos básicamente están determinados por estas formas restrictivas. Esta perspectiva analítica desafía los metarrelatos develándolos como quimera de la verdad. Los metarrelatos teóricos no prestaron atención al protagonismo de las luchas de poder libradas en estos escenarios "otros", y que corroerían finamente sus propias estructuras de interpretación subyacentes. Su atención se fijaba en las contradicciones antagónicas institucionalizadas contra el Estado burgués y su estructura económica. Foucault rasgó el velo tendido por los discursos de "verdad" de los metarrelatos.

Este destacado intelectual desparecido de manera prematura, re direccionó la mirada de las prácticas discursivas objetivadas en las estructuras sociales y en la cotidianidad de los sujetos, donde el poder circula como saber-poder. Con él se asume que el poder se genera y realiza sobre el tejido de un actuar común, "ordinario" de los sujetos. En este sentido el poder no es autopoiético; su acción como discurso dinámico se mueve y expresa en la multitud de actos que a diario son protagonizados por el individuo, guiando su posibilidad de conducta y poniendo en orden sus efectos posibles.

\section{La ciudadanía, formación discursiva del saber-poder}

La construcción ciudadana como forma positiva moderna deja de ser una elemental función normativa de la relación sujetoEstado. Con Foucault se pueden ver otras aristas, otros tonos que dan forma a la totalidad cromática del cuadro social. Las relaciones de poder como cuerpo de forma múltiple y sutil se manifiesta en todos los niveles y ámbitos cotidianos, particulares o micropoderes, reelaborándose y reafirmándose, en un proceso no neutral que encuentra espacios de resistencia continuados con la racionalidad de imposición o control.

De tal manera que los mecanismos del saber-poder entrecruzan la esfera pública, privada y cotidiana del sujeto, siendo el ciudadano moderno una expresión de tal circulación de representaciones discursivas. En este sentido, debemos considerar que el ciudadano como sujeto construido por saber-poder, también tiene una dimensión de norma positiva. Se da pues una forma de regulación tácita de ley y coerción. Sin embargo, la perspectiva de su análisis al verla desde el sentido foucaultiano, nos lo mostrará inserto en la lógica de ser esta, una relación constituida, desde determinadas relaciones de saberpoder.

Podemos asumir como modelo, extrapolando, que el dispositivo panóptico y su relación binaria disociada ver-ser visto, controla los comportamientos ciudadanos en las democracias consumistas de la modernidad. Construidas como tales en el entramado de las relaciones disciplinarias múltiples que la componen, todos ven sus manifestaciones aparentes y participan de ellas, ya como corrientes de consumo, como sistema asimilado de participación, etc., pero no vemos los hilos que subyacen en la raíz misma de la vigilancia permanente que el sistema mantiene. Es el panóptico moderno, no se ve pero ejerce un poder control. Es el frenesí del disciplinamiento ciudadano introyectado, la esencia misma del vigilante que se anda dentro.

Quizás un idea reto que se puede extraer de Foucault es la necesidad de deconstruir la ciudadanía en tanto categoría correctiva que engulle cualquier desarrollo libre de la realización del sujeto. La noción de ciudadanía se compone de barreras 
carcelarias naturalizadas en el matiz de la cotidianidad encubierta por el poder. Esta relación se encuentra mediada por el acumulado-sustrato cultural que se introyectan en el sujeto, en un proceso dinámico de configuración y reconfiguración, aun antes que este tenga conciencia de la naturaleza disciplinaria que lo constituye y dimensiona en todo su esplendor y magnificencia.

El dispositivo panóptico en su esencia ha logrado su propósito y consigue alzar su triunfo como razón válida de un sistema de representación que imprime disciplinamiento ciudadano mediante la organización de sus emplazamientos y su tiempo.

Las relaciones de poder múltiples, como señala Foucault en la microfísica del poder, atraviesan, caracterizan y terminan construyendo el cuerpo social. Son relaciones de poder que no pueden disociarse, ni funcionar sin una producción, una circulación y un funcionamiento del discurso. Por tanto, como ya se dijo con anterioridad, la naturaleza del poder no es una cualidad autopoiético, se conduce y es aprehendida en el interior de la sociedad por medio de prácticas reales y efectivas. (Foucault, Michel, 1991).

La ciudadanía en tanto sujeto disciplinado por el poder, se mueve en un tiempo que es homogéneo, disciplinado, sincrónico. El reto es transformar este marco de condicionalidad que tal categoría establece $y$ atreverse a avizorar un horizonte emancipatorio diferente cuya prosecución proponga el rompimiento de la cotidianidad introyectada a manera de norma naturalizada y consustancial que recluye al sujeto ciudadano.

No existe pues, un sujeto como ciudadano en sí mismo, preexistente al saber-poder.
Es por medio del circuito discursivo que se puede establecer la existencia de la ciudadanía como producto de una acción disciplinaria que da cuerpo, clasifica y objetiva. Es una acción que tiene su ocurrencia dentro de una analítica que apunta, tanto al conjunto de conocimiento, como al control. Desde esta perspectiva, se puede comprender la visión de Foucault y percibir este circuito donde el discurso configura al sujeto ciudadano y hace posible su emergencia dentro en un determinado marco histórico social.

\section{Conclusiones}

La propuesta de Foucault sugiere visos de acción y análisis de vigencia singular, validos hoy como en el futuro, en lo fundamental dentro de los marcos de condicionalidad políticas aparentemente normativas del sistema capitalista y su posicionamiento teórico neoliberal que han dejado sin base a gran parte de las propuestas teóricas alternativas. Más allá de eso, lo cierto es que se necesitan nuevos caminos de abordaje teóricos para los diversos, múltiples y nuevos problemas sociales. Es allí donde Michell Foucault y su propuesta se dimensiona como un reto permanente que debe de asumirse, con sus enfoques teóricos vigentes y de actualidad.

De su lectura se puede inferir que si bien la relación de poder-saber se deja ver objetivada en el sujeto, es indudable también, la gran carga que lleva sobre si la institución Estado como matriz de un modelo normativo que también individualiza. Este razonamiento hace que la propuesta deba ser la consecución de la libertad tanto del modelo de Estado como de la forma individualizante que dimana, proponiendo dentro de un horizonte posible dar lugar a otra subjetividad.

El pensamiento de Foucault adquiere en nuestro tiempo mayúsculo interés y 
utilidad. Su forma de analizar las relaciones de poder brindan un marco teórico que abre una multiplicidad de posibilidades para realizar estudios mas integrales que tomen como referentes los diversos tejidos que marcan los mecanismos de control ocultos tras la modernidad tecnológica de nuestras sociedades.

En ese sentido por la vigencia de sus aportes y la amplitud que brida su mirada, Michell Foucault constituye para los cientistas sociales un reto permanente que debemos asumir.

\section{Referencias Bibliográficas}

Michel Foucault. Vigilar y Castigar, nacimiento de la prisión. Ed. Siglo XXI. México. 2000.

Michel, Foucault. Microfísica del poder. 3ra Edición. Ediciones de La Piqueta. España 1991. 